\title{
Applying RADAR with new business postgraduates
}

Journal of Information Science

2014, Vol. 40(I) 25-27

(c) The Author(s) 2013

Reprints and permissions:

sagepub.co.uk/journalsPermissions.nav

DOI: $10.1177 / 0165551513510094$

jis.sagepub.com
John G. Cullen

National University of Ireland Maynooth, Ireland

\begin{abstract}
In a recent 'research in practice' article in the Journal of Information Science, Mandalios introduced the RADAR tool, which she designed to assist students evaluate online information. She pointed out that the tool, although supported by preliminary qualitative research conducted at her own institution, required further empirical investigation. This brief communication aims to contribute empirical evidence which supports the efficacy of RADAR as a tool for evaluating online information resources by discussing student feedback on the application of the tool in an introductory session to a taught postgraduate business class. The context in which the RADAR tool was deployed is discussed, data on student reactions to it is reported and implications for future research are discussed.
\end{abstract}

\section{Keywords}

critical thinking; evaluating web resources; information literacy; RADAR; student research

\section{Introduction}

Mandalios [1] recently introduced the RADAR tool as an approach to assist students to critically evaluate information resources that were found online. Although learners are increasingly comfortable with online resources, she highlighted that many are unaccustomed to critically evaluating these items in a rigorous manner. In other words, the ability to find larger quantities of information online did not necessarily result in higher quality resources being incorporated into research assignments. Mandalios reviewed a number of research projects which appear to suggest that the ubiquity of internet usage in daily life and the high level of familiarity amongst traditional students with the online world negatively impacts their ability to reflexively appraise the resources sourced by students for usage in their research projects. Additionally, she cites the work of library professionals such as McGuinness [2], who have found that many faculty are unwilling to take responsibility for incorporating information literacy into their teaching.

Mandalios utilizes the metaphor of 'the ocean' to describe the breadth of online resources available to students and proposes that RADAR be used to assist its navigation. She describes conducting a 'live' classroom-based evaluation of potential online research resources by assessing them in terms of their relevance, authority, date, appearance and reason for writing. The five elements constitute the acronym 'RADAR'. Without replicating the classroom material Mandalios usefully provides in her 'research in practice' article, by relevance she encourages students to consider how the information used is relevant to a specific student assignment. The concept of authority asks students to critically reflect both on the personal or corporate identity of the authors of information sources and their credentials for producing accurate and reliable information or theory. The date rubric invites students to think about the timeliness of the information, and whether the date of the publication is significant to their assignment. Appearance asks students to consider the professionalism of the production of the online resource. Finally, reason for writing asks about the motives of the author and encourages students to think about potential publication biases that might be held by individuals or corporate entities who choose to share information online. Mandalios points out the palindromatic nature of the RADAR tool: students do not need to use it in a step-by-step fashion, as it allows students to commence evaluation at any stage of the process.

Corresponding author:

John G. Cullen, School of Business, National University of Ireland Maynooth, Maynooth, Co. Kildare, Ireland.

Email: John.g.cullen@nuim.ie 
Mandalios assessed the usability of the RADAR tool through a preliminary case study, based on diary studies in her home institution in Greece. Although the results of the study were very strong and reported that students found RADAR to very useful, uncomplicated and straightforward, Mandalios highlights the limitations of her research on the tool.

Clearly this small-scale study was very limited in both scope and purpose, and it makes no claim to supply evidence that positive student perceptions of RADAR might also translate into effective evaluative competence. However, I do feel that is has provided a very useful preliminary indication that RADAR merits consideration and further investigation. [1, p. 477]

The research in this brief communication is also small scale, but it represents a first attempt to contribute to research on the RADAR information literacy tool for students by investigating reactions of students participating in a postgraduate business course to the application of RADAR. Additionally, it represents the first attempt, to the author's knowledge, to study the application of RADAR outside the educational context in which it was first developed. In the next section this research is first discussed in relation to information literacy in business education in general, and then specifically to the context in which the research was undertaken. In the final section, the results of the research are discussed and avenues for further research are suggested.

\section{The research context}

Calls for more rigorous critical writing and reflexive research skills for business students at all levels have increased in recent years from within the business academy [3] and from employers [4]. Much research on the role of developing critical mindsets amongst business students $[4,5]$ highlights the inter-relationship between rigorous research and writing critically. Studying business at university level typically requires students to engage with a range of different topics (e.g. organisational behaviour, finance, information management, operations management, IT, strategy, economics, marketing, etc.). This means that, when students commence studying business, they are unlikely to be familiar with all its associated fields, and their accompanying citing and research traditions.

This was the case in the introductory module on a taught postgraduate business module where the research for this brief communication was undertaken. The participants came from a variety of national, educational and experiential backgrounds, and it was decided to use the RADAR tool as a means of instructing students unfamiliar with business research resources to how to assess the quality of published material. The cohort of students involved in this research was slightly larger than Mandalios's group (43 students as opposed to 25), and they were exposed to the tool over one full day rather than in two separate classes. Students were presented with an 'open' business-type question and asked in groups of six or seven to identify five quality sources that would support further work on the question. Nearly $66 \%$ of the class were female $(n=28)$, almost $21 \%$ had a first language which was not English $(n=9)$ and almost $44 \%(n=19)$ had significant occupational experience and had worked, or were working, in some form of managerial capacity. Group membership was allocated to represent the diversity of experience in the class. After a period of approximately 40 minutes of searching, the groups presented their results. Then a presentation on RADAR similar to that described by Mandalios [1] was given and the students were allowed another 40 min to continue conducting their search for information. Immediately after the conclusion of this exercise the students were asked to complete a brief questionnaire which asked the following questions.:

(1) Did you find the RADAR tool easy to understand?

(2) Did you find the RADAR tool easy to apply?

(3) Do you think the RADAR tool will improve the quality of your continuous assessments in the future?

(4) Are there any aspects of the RADAR tool that you found difficult to understand or apply?

Students were asked to answer on a scale that permitted the following answers: 'Not at all', 'A little', 'Somewhat', and 'Very much'. Question (4) was open and an answer box was provided for students to answer in this if they wished and just under half of the class $(n=21)$ elected to do.

\section{Results and research implications}

The results of this small piece of research upholds Mandalios's [1] findings that students found RADAR to be easily comprehensible, memorable and readily applicable to the evaluation of online resources, and that it improved student confidence about their future research activities. Nearly $63 \%$ of the class $(n=27)$ answered 'Very much' to the question 'Did you find the RADAR tool easy to understand?' The next highest number of responses to this question was 
'Somewhat' $(33 \%, n=14)$. Almost $50 \%$ of the class $(n=21)$ answered 'Very much' to the question: 'Did you find the RADAR tool easy to apply?' However, almost $42 \%$ of respondents $(n=18)$ answered 'Somewhat'. It must be borne in mind that many of the qualitative format answers provided to question (4) stated a belief that the students' usage of the tool would improve in time with practice. This belief about the efficacy of RADAR as a tool with the potential to improve assessment of online information is upheld by the response rate to question (3). The strongest level of response was found in the answer to the third question: 'Do you think the RADAR tool will improve the quality of your continuous assessments in the future?' Almost $70 \%$ of respondents $(n=30)$ answered 'Very much' to this question. An interesting finding was that the level of organizational or professional experience, gender or having English as a first language did not impact significantly on the results returned.

This research is broadly consistent with Mandalios's discovery about positive student responses to the introduction of the RADAR tool. Mandalios conducted her research with an English composition course; this research was conducted with a slightly larger introductory business course for non-business graduates. The similarities in responses to RADAR across both studies, and the diversity found in the class in the current study, supports Mandalios' statement that 'All user ages and levels of sophistication can be catered for as its level of sophistication can be ratcheted up according to need and user willingness' [1, p. 477]. However, like Mandalios's study, this work was primarily focused on students' first engagement with RADAR, and although it appears to do much to encourage students, future research should focus on student perspectives of the longer-term impact on academic practice through using RADAR.

\section{References}

[1] Mandalios J. RADAR: An approach for helping students evaluate Internet sources. Journal of Information Science 2013; 39: $470-478$.

[2] McGuinness C. What faculty think: Exploring the barriers to information literacy development in undergraduate education. Journal of Academic Librarianship 2006; 32: 573-582.

[3] Antonacopolou EP. Making the business schools more 'critical': Reflexive critique based on phronesis as a foundation for impact. British Journal of Management 2010; 21: S6-S25.

[4] Cullen JG. The writing skills course as an introduction to critical practice for larger business undergraduate classes. International Journal of Management Education 2011; 9: 25-37.

[5] Cunliffe A. On becoming a critically reflexive practitioner. Journal of Management Education 2004; 28: 407-426. 